Article

\title{
Improving Energy Efficiency of Flexible Pneumatic Systems
}

\author{
Slobodan Dudić ${ }^{1}$, Vule Reljić ${ }^{1}\left(\mathbb{D}\right.$, Dragan Šešlija ${ }^{1}$, Nikolina Dakić ${ }^{1, *}$ and Vladislav Blagojević ${ }^{2}$ \\ 1 Faculty of Technical Sciences, University of Novi Sad, Trg Dositeja Obradovica 6, 21000 Novi Sad, Serbia; \\ dudic@uns.ac.rs (S.D.); vuketa90@uns.ac.rs (V.R.); seslija@uns.ac.rs (D.Š.) \\ 2 Faculty of Mechanical Engineering, University of Nis, Aleksandra Medvedeva 14, 18000 Nis, Serbia; \\ vlada@masfak.ni.ac.rs \\ * Correspondence: nikolinadakic@uns.ac.rs
}

Citation: Dudić, S.; Reljić, V.; Šešlija,

D.; Dakić, N.; Blagojević, V.

Improving Energy Efficiency of

Flexible Pneumatic Systems. Energies

2021, 14, 1819. https://doi.org/

10.3390/en14071819

Academic Editor: Oscar Barambones

Received: 10 February 2021

Accepted: 15 March 2021

Published: 24 March 2021

Publisher's Note: MDPI stays neutral with regard to jurisdictional claims in published maps and institutional affiliations.

Copyright: (c) 2021 by the authors. Licensee MDPI, Basel, Switzerland. This article is an open access article distributed under the terms and conditions of the Creative Commons Attribution (CC BY) license (https:// creativecommons.org/licenses/by/ $4.0 /)$.

\begin{abstract}
During pneumatic control system design, the critical value for choosing the appropriate pneumatic actuator is the weight of the workpiece. In the case of flexible production systems, which are the core part of the Industry 4.0 (I4.0) concept, the weight of the workpieces is often variable, since the crucial feature of this kind of production is its ability to deal with variable parts. Therefore, in order to deal with the variable weight of parts, a pneumatic actuator is chosen according to the heaviest part. However, according to another I4.0 principle, energy efficient operation of machines, the previous criteria for choosing a pneumatic actuator is energy efficient only when handling the heaviest part. In all other cases, operation of the pneumatic actuator is suboptimal in terms of energy efficiency. Aiming to solve this problem, this paper considers the possibility of using a new pressure regulator instead of traditional manually adjusted pressure regulators. This regulator provides operating pressure modification in real-time in accordance with the weight of the workpieces. In this way, the optimal compressed air consumption is ensured for each workpiece. Implementation of this device has yielded significant energy savings; however, the value is variable and depends on working task characteristics.
\end{abstract}

Keywords: energy efficiency; energy savings; flexible production systems; automatically controlled pressure regulator; product mix

\section{Introduction}

A modern approach to production development is based on the I4.0 concept. It is being implemented more often in advanced production systems throughout the world. This approach defines a few key foundations that will be shown in detail in Section 1.1. Some of them can oppose each other when simultaneously used. An example of such opposition is the need for both system flexibility, meaning the possibility of production of different workpieces, and energy efficiency. This, especially, comes to the front with pneumatic control systems, which are widely used due to the compressed air favorable characteristics, but the majority of those uses are energy inefficient. Many authors have made efforts to find solutions to this problem in order to improve the energy efficiency of pneumatic systems, which will be shown in Section 1.2.

When pneumatic actuators are used for handling workpieces, they are dimensioned according to the heaviest workpiece, as it requires the highest force for its uplifting. For dimensioning the actuators, the highest recommended compressed air pressure value ( 6 bar) is used [1]. For achieving this pressure value, the traditional manually adjusted pressure regulators were mainly used. These regulators keep, once adjusted, compressed air pressure level constant during time. However, if the same actuator is used for handling other, lighter workpieces, the installed actuator will be unnecessarily forceful, using more compressed air energy than required. In order to respect a requirement of the I4.0 concept, which is the energy efficient work principle, in these conditions, one of the measures for increasing energy efficiency can be taken. The reduction of the compressed air consumption 
of pneumatic components and the effective utilization of the exhaust air are among the most effective measures for energy savings in this field [2,3]. In this case, reducing the consumption of compressed air energy is achieved by using a specially developed, automatically controlled pressure regulator [4]. This regulator has the possibility of communication with the main control system, which is used to adjust the compressed air pressure level in the actuator depending on the weight of the workpiece in real time. This device is shown in Section 2.2.

To prove the energy saving possibility using the automatically controlled pressure regulator, a specially developed setup was used: a circular manipulator [5]. The basic idea is for it to serve as buffer storage for an automated production line, as well as to simulate the continuous work of the production line operating in I4.0 conditions. This is shown in detail in Section 2.1. The flexibility of this device can be recognized in the possibility of gripping and handling three dimensionally similar, yet different workpieces. These workpieces differ in shape, type of material, and mass and can appear randomly in the system. In extreme cases, the size of the series can be one, meaning every following workpiece differs from the previous.

The largest compressed air energy consumer of this device is the pneumatic cylinder, which lifts workpieces from the bottom position (storage exit) to a higher level (storage input). It was dimensioned to be able to handle the heaviest workpiece. The automatically controlled pressure regulator is connected to the cylinder piston chamber in order to modify the technological characteristics of the setup, specifically the cylinder operating pressure, so that it can adapt to the required characteristics of the pneumatic system for each workpiece.

In this paper, the energy efficiency is identified by comparing the amount of compressed air consumed in the control system equipped with the automatically controlled pressure regulator to that in traditional control system under the same working conditions and work cycles.

\subsection{Industry 4.0 and Flexibility of Production Systems}

The basic concept of Industry 4.0 [6-9] was presented for the first time at Hannover Fair in 2011. Industry 4.0 is defined as a key transformation in the history of factory automation aiming to:

- Enable the production of various products within the same production line,

- Reduce the time of response to specific, individual requests of customers,

- Optimize production whilst saving energy, material, and money, and

- Collect, share, and utilize information with the purpose of enabling a continuous exchange of information among all devices within the production line in order to realize the concept of "smart" factories.

It is expected that the use of this approach will increase the productivity of manufacturing, which will additionally instigate industrial growth [10].

It is possible to meet set requirements in modern, flexible manufacturing systems (FMS) [11,12]. FMS represent the most technologically advanced manufacturing unitscells with a high level of automation based on group technology utilization [13-15]. These systems are able to produce a number of different workpieces (product mix) [16] within a very short time, intended for transitioning from manufacturing one type of workpiece to another without modifying their equipment. It is necessary to emphasize that the differences between the workpieces processed by such a system cannot be big, i.e., it is not possible to manufacture, for example, airplane parts and sports equipment at the same time.

To accomplish the set tasks in such systems, it is necessary to use different technologies and control algorithms. For example, workpieces are utilized as "smart" products to transfer important information from one machine to another, e.g., some of its current important characteristics, the level of processing and preparedness of workpieces, etc. For this purpose, Radio Frequency IDentification (RFID) technology is frequently used. RFID technology provides contactless reading of the information from the tags and writing infor- 
mation into the tags. The same operation can be executed using Near Field Communication (NFC) technology, in cases where the two workpieces that need to exchange information are positioned within $10 \mathrm{~mm}$ distance. Other than the information exchange among machines via workpieces and/or workpiece carriers, it is exceptionally important for machines to exchange information among themselves (Machine-to-Machine, M2M), as well as maintain the communication between the operator and the machines (Human-to-Machine, H2M) at a high level. Additionally, it is important to constantly monitor control process parameters, such as energy consumption (e.g., measure the compressed air consumption), operating pressure, temperature parameters, test the filter contamination, etc., and adapt the control process to minimize the deviations from the required values.

Therefore, the current direction of the development of modern production systems including pneumatic control systems, in some cases, implies their growth from the form of standard mechatronic to the networked cyber-physical systems. In this way, continuous information flow is enabled, as well as variation of the process control parameters (for example, the operating pressure) in real time and in timely response in accordance with current requests.

\subsection{Energy Efficiency of Compressed Air Systems}

The state of art in the field of energy efficiency of pneumatic control systems shows that many authors have made efforts to achieve improvements concerning energy efficiency of pneumatic systems in order to reduce costs and reduce energy consumption in different ways, such as the development of new control algorithms and schemes, reducing air leakage, etc. In accordance with what has been previously mentioned, a newly developed booster valve was proposed in [17,18], with the possibility of collecting and reusing compressed air energy in order to reduce the compressed air consumption. Another possible scheme, containing a fast switching on/off valve, was introduced in [19]. That valve is controlled using a pulse-width modulation (PWM) technique associated with another Proportional-Integral (PI) controller, and whose role is to connect the chambers of the cylinder to reduce the compressed air consumption of pneumatic positioning systems with external loads. An exergy-related analysis was used in [20] to evaluate the pneumatic systems efficiency, and it was shown that this analysis is the most suitable tool. An energy saving approach, achieved by adding a by-pass flow-enabling valve between the chambers of the cylinder, is proposed in [21,22]. Instead of using proportional valve, the joint application of a PWM and by-pass chamber control of the pneumatic rodless cylinder was introduced in [23]. An important advantage of PWM control is lower consumption of compressed air. The air leakage reduction for improving the energy efficiency of the pneumatic system is proposed in [24,25]. Additionally, a number of authors have worked on improving the energy efficiency of pneumatic actuators utilizing circuits that were more complex, for example, a dual pressure supply [26] and air expansion energy [27].

This paper presents a new approach to reducing the compressed air consumption of pneumatic control systems. The aim of the research shown in this paper is to develop a new pneumatic system that operates at variable compressed air pressure levels in the working cylinder stroke depending on the workpiece entering the process.

Namely, the majority of pneumatic components are manufactured to withstand operating pressure up to 10 bar. However, in industrial practice, lower pressure levels are often sufficient for executing the intended operations, so the pressure level most commonly used in industrial processes is 6 bar. For certain operations of some systems, even 6 bar of pressure is excessive [1]. Therefore, the optimal compressed air pressure level can be defined as the pressure sufficient for undisturbed operating of the actuator. The reduction of operating pressure causes a decrease of compressed air consumed by the actuator, which can possibly lead to significant energy savings [28]. A pressure regulator is a component most commonly used for compressed air pressure reduction. Since the pressure regulator allows air flow in one direction only, it is most commonly connected in parallel to a nonreturn valve. Another way of achieving the same outcome is connecting a quick exhaust 
valve between the pressure regulator and the cylinder piston chamber. The second option was chosen for this purpose, as the quick exhaust valve will not only allow the flow of the exhaust air, but will also provide a faster exhaustion time than a simple non-return valve. Additionally, for this purpose, an automatically controlled pressure regulator was specially designed in order to provide variable pressure levels.

The proposed pneumatic system, supplied with various levels of compressed air pressure, provides the reduced consumption of compressed air. Lower compressed air pressure in the cylinder chambers induces the reduction of compressed air consumption.

\section{The Developed Experimental Control System and Devices}

All experimental tests were done using the experimental control system, the flexible pneumatic circular manipulator [5]. The circular manipulator was developed at the Faculty of Technical Sciences in Novi Sad, Serbia, where it is used for the purposes of education and research.

\subsection{Flexible Pneumatic Circular Manipulator}

The hardware realization of the manipulator, which consists of five double-acting pneumatic cylinders (marked with A-E), one pneumatic gripper (marked with $\mathrm{H}$ ), and the corresponding mechanical construction, intended for bearing and guidance of the actuators, as well as for handling and storing the workpieces in use, is shown in Figure 1a. A travel-step diagram of the manipulator is shown in Figure $1 \mathrm{~b}$.

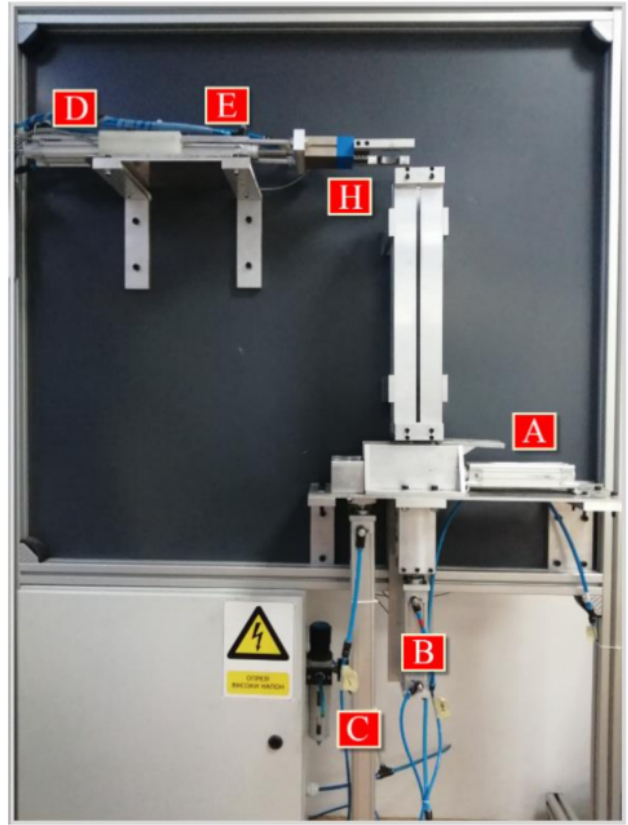

(a)

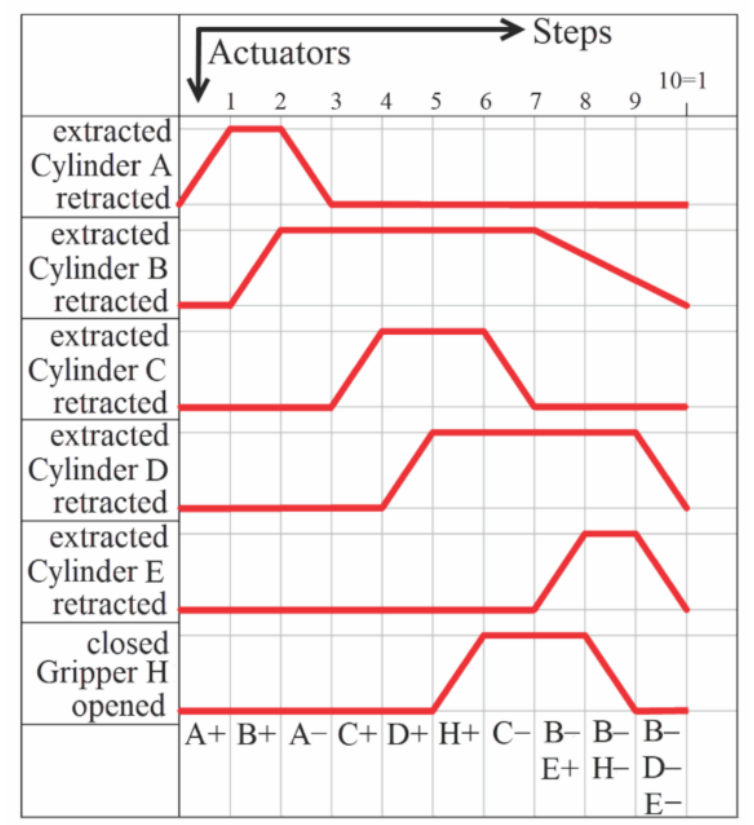

(b)

Figure 1. Pneumatic circular manipulator (a) hardware realization. Reproduced from [5], IJOE, 2018. (b) travel-step diagram.

In accordance with the defined operations and system requirements, the appropriate pneumatic elements were dimensioned and chosen:

- $\quad \mathrm{A}, \mathrm{B}, \mathrm{D}$, and E-Festo double-acting pneumatic cylinders with $32 \mathrm{~mm}$ piston diameter and a $100 \mathrm{~mm}$ stroke length, order no. DNC-32-100-PPV-A. Cylinders D and E form a multi-position cylinder.

- C-Festo double-acting pneumatic cylinder with $32 \mathrm{~mm}$ piston diameter and a $600 \mathrm{~mm}$ stroke length, order no. DNC-32-600-PPV-A.

- $\quad \mathrm{H}-$ Festo pneumatic gripper, order no. HGP-25-A-B. 
All of the required valves and other pneumatic equipment used for the manipulator are placed in a pneumatic control cabinet. The manipulator is controlled by the Festo Programmable Logical Controller (PLC) FC660.

The workpieces are positioned in the vertical storage. At the lowest point, horizontally positioned cylinder A pushes one workpiece forward, and the vertically positioned cylinder $\mathrm{C}$ lifts it. Vertically positioned cylinder B holds the remaining workpieces temporarily and slowly descends them to avoid impact. Finally, the multi-positional cylinder (composed of two cylinders with identical characteristics, $\mathrm{D}$ and $\mathrm{E}$ ) that carries the pneumatic gripper accepts the workpiece and transfers it back to the top of the vertical storage. The workpieces are moved through the storage due to gravity. This way, by repeating the operating cycle, the workpieces circulate through the experimental system and from that comes the name of the manipulator [5].

For the purpose of this research, three types of workpieces of similar dimensions were designed. In Figure 2, these workpieces are marked as WP1, WP2, and WP3. The workpieces are made of different materials and, therefore, their weights differ. WP1 (mass $\mathrm{m}_{1}=0.5 \mathrm{~kg}$ ) is made of plastic, WP2 (mass $\mathrm{m}_{2}=1 \mathrm{~kg}$ ) is made of steel with a hole inside of it in order to reduce its weight, and WP3 (mass $\mathrm{m}_{3}=4 \mathrm{~kg}$ ) is made out of steel.

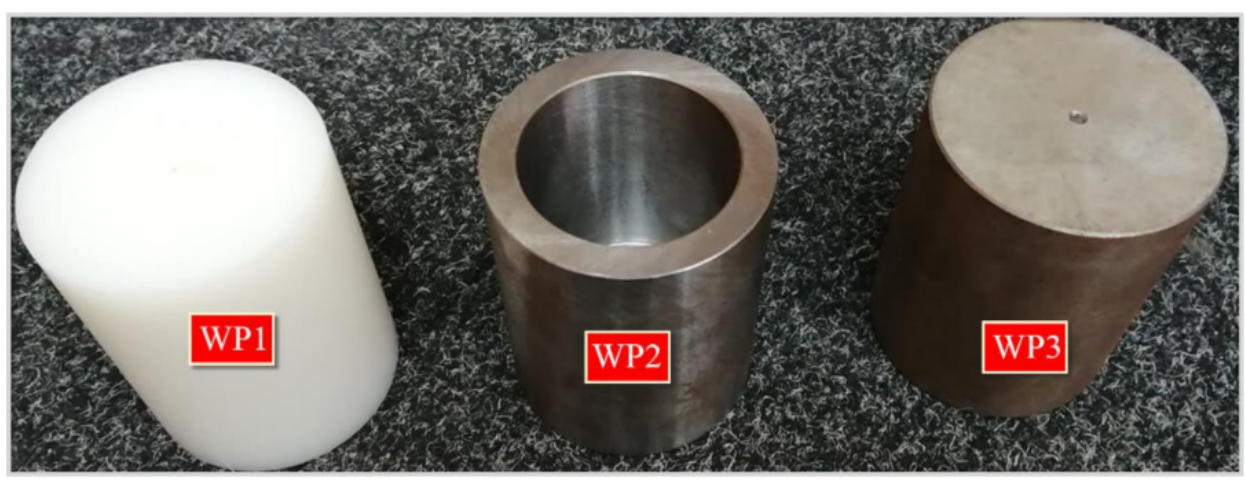

Figure 2. The three types of workpieces.

The pressure required for handling the workpieces is determined using the following expression:

$$
F_{a c t}<F_{e f f}=0.9 \times F_{t h}=0.9 \times p \times A
$$

where $F_{\text {act }}$ is the actuator opposing force, $p$ is the compressed air operating pressure in the system, and $\mathrm{A}$ is the cylinder surface area. The effective piston force $\left(F_{\text {eff }}\right)$ reduces for approximately $10 \%$ compared to the theoretical force $\left(F_{t h}\right)$ due to frictional and other types of resistance [1]. In the case of cylinder extracting, the required pressure level can be calculated using the inequalities:

$$
p>\frac{F_{a c t}}{0.9 \times A^{+}} ; A^{+}=\frac{D^{2} \times \pi}{4} ; D=\text { const. }
$$

where $D$ is the piston diameter of the chosen cylinder, and $A^{+}$is the cylinder piston surface area.

In a specific case, when only workpieces lifting is analyzed (cylinder $C$ as a part of the pneumatic circular manipulator), the actuator opposing force is gravity force. Therefore, the required pressure level can be derived as:

$$
p_{i}>\frac{4 \times m_{i} \times g}{0.9 \times D^{2} \times \pi}
$$

where $g$ is gravitational acceleration, $m_{i}$ is the mass of the currently processed workpiece, and $p_{i}$ is the operating pressure required for handling the given workpiece (for the appropriate actuator). 
The expression (3) proves that the actuator operating pressure required for handling workpieces depends on the mass of those workpieces, i.e., that the compressed air pressure is a function of mass of the handled workpieces:

$$
p_{i}=f\left(m_{i}\right)
$$

Since the aim of this research is to establish a new approach to the reduction of compressed air consumption, calculation of its value is given in the following equations. The dependence between compressed air consumption and actuator operating pressure is given as [1]:

$$
Q=V \times \frac{p+p_{a}}{p_{a}}=A \times h \times \frac{p+p_{a}}{p_{a}},
$$

where $Q$ is compressed air consumption, $V$ is the actuator volume and can be calculated as cylinder surface area $(A)$ multiplied by the stroke length $(h), p$ is operating pressure in the system, and $p_{a}$ is atmospheric pressure. Compressed air consumption per cycle for one cylinder is a sum of consumption during a forward stroke (cylinder extracting) and a return stroke (cylinder retracting) and can be derived as:

$$
\begin{aligned}
Q_{c i}=Q^{+}+Q^{-}=h \times \frac{p_{i}+p_{a}}{p_{a}} & \left(A^{+}+A^{-}\right)=h \times \frac{p_{i}+p_{a}}{p_{a}}\left[\frac{D^{2} \times \pi}{4}+\frac{\left(D^{2}-d^{2}\right) \times \pi}{4}\right] \\
& =h \times \frac{p_{i}+p_{a}}{p_{a}} \times \frac{\pi}{4} \times\left(2 D^{2}-d^{2}\right),
\end{aligned}
$$

where $Q_{c i}$ is compressed air consumption per cycle, $Q^{+}$is consumption per forward stroke, $Q^{-}$is consumption per return stroke, $A^{+}$is the cylinder piston surface area, $A^{-}$is the annulus surface (the difference between cylinder piston and piston rod surface area), $D$ is piston diameter, and $d$ is piston rod diameter. As values of $D, d$, and $h$ are constant (for the chosen cylinder), it is obvious that compressed air consumption is the function of operating pressure:

$$
Q_{c i}=f\left(p_{i}\right)
$$

In accordance with the chosen components of the system (pneumatic cylinders and pneumatic gripper), and by using Equation (6), it is possible to calculate and simulate the theoretical compressed air consumption of the circular manipulator per cycle. In this simulation, the operating pressure for extraction of the cylinder $C$ was varied ( $2 \mathrm{bar}, 4 \mathrm{bar}$, 6 bar), and operating pressure for all other operations was set to the highest recommended compressed air pressure value (6 bar). The results are shown in Table 1.

Table 1. The theoretical compressed air consumption of the circular manipulator per cycle.

\begin{tabular}{cc}
\hline The Operating Pressure of Cylinder C Extracting (bar) & $\begin{array}{c}\text { The Compressed Air } \\
\text { Consumption (1) }\end{array}$ \\
\hline 6 & 10.536 \\
4 & 9.583 \\
2 & 8.631 \\
\hline
\end{tabular}

When determining which of the two systems is more efficient, it is necessary to compare their compressed air consumption values and define percentual savings value:

$$
Q_{s}[\%]=\frac{\Delta Q}{Q_{i}} \times 100 \%=\frac{Q_{i}-Q_{j}}{Q_{i}} \times 100 \% ; Q_{i}>Q_{j},
$$

where $Q_{i}$ is compressed air consumption of $i$ th system, $Q_{j}$ is compressed air consumption of $j$ th system, and $Q_{s}$ presents percentual consumption savings (the indicator of the energy efficiency of the new, $j$ th system). 


\section{Pneumatic Control Scheme}

The pneumatic control scheme of the manipulator is given in Figure 3. In order to more easily understand the scheme, the actuators are displayed in their actual positions. Each cylinder has the possibility of speed regulation via one-way flow control valves.

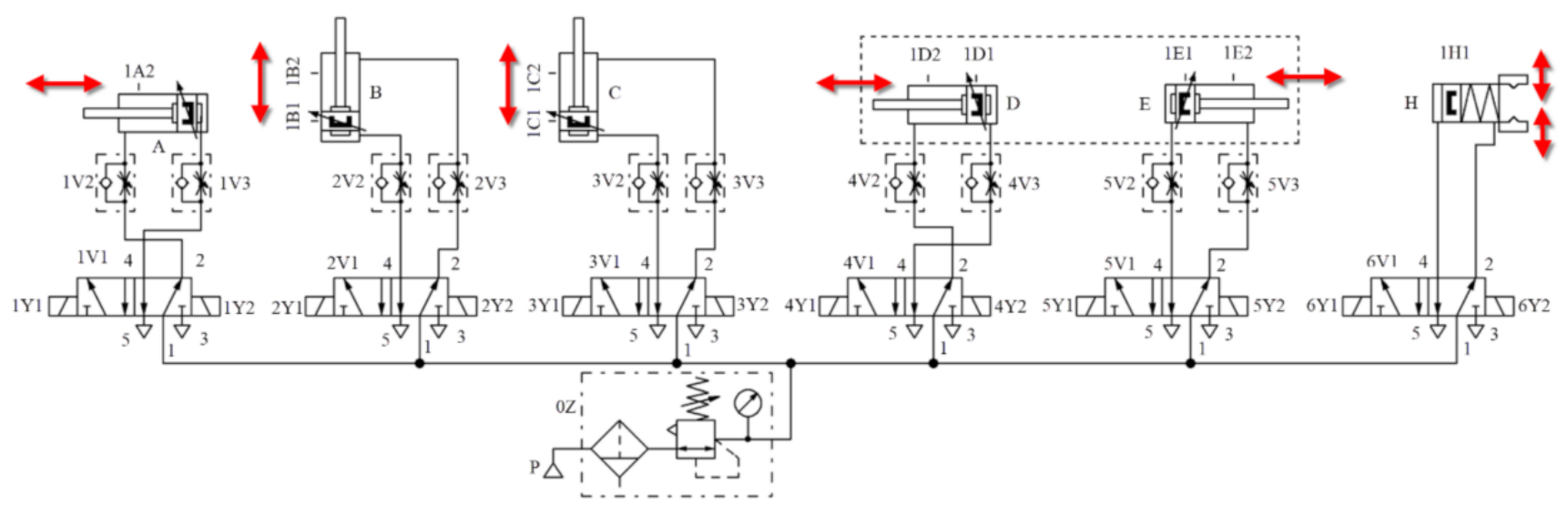

Figure 3. Initial pneumatic control scheme of the manipulator.

\subsection{Automatically Controlled Pressure Regulator}

Though there are plenty of different electrical pressure regulators (for example series MS-LRE by Festo or series ITV by SMC) or proportional pressure regulators (for example series VPPM, VPPE, MPPE, or MPPES by Festo) on the market, in this paper, a new automatically controlled pressure regulator [4] with the possibility of remote control was developed. The mentioned pressure regulator is of lower cost and more suitable for laboratory work and less complex systems, even for individual actuators, because it enables lower compressed air flow. In addition, the developed pressure regulator can be upgraded by implementation of WiFi communication, which would eliminate the need for wire conductors and enable remote control from any location. This is in conjunction with the I4.0 concept, that is with constant variation of process control parameters in accordance with the current requirements. The mentioned pressure regulator is shown in Figure 4 and, in this case, is used for adjusting the value of the air pressure in cylinder $C$ of the pneumatic circular manipulator.

The working principle of this device [4] is based on adjusting the standard pressure regulator (order no. 539756, by Festo) to the required pressure value by turning the adjusting screw. The adjusting screw is connected to the stepper motor (NEMA 14) shaft, and based on the difference between the current and required pressure value, the motor can make the corresponding number of steps. Microcontroller Arduino Uno is used for motor control.

The way to operate the standard pressure regulator was determined experimentally by first setting the regulator outlet pressure to $0 \mathrm{bar}$ and measuring its new value after rotating the stepper motor shaft for a certain number of steps. The number of steps that the stepper motor made was read every time the outlet pressure reached a previously defined value (increased in 0.25 bar) until the pressure value reached 6 bar. Using the obtained results, the dependence of outlet pressure from the number of stepper motor steps was determined, as is shown in graph in Figure 5 (left position). An inverse polynomial function, which shows the opposite dependence (dependence of the number of stepper motor steps from the regulator outlet pressure), was obtained using the MATLAB (MathWorks, Inc., Natick, MA, USA) polyfit function (Figure 5, right position) [4]:

$$
\begin{gathered}
y=0.5096 \times x^{7}-10.9791 \times x^{6}+93.0751 \times x^{5}-387.9048 \times x^{4}+790.5952 \times x^{3}-594.9242 \times x^{2} \\
+402.545 \times x+4620.2849
\end{gathered}
$$


where $y$ is the number of steps of the stepper motor and $x$ is the difference between current and desired pressure value.

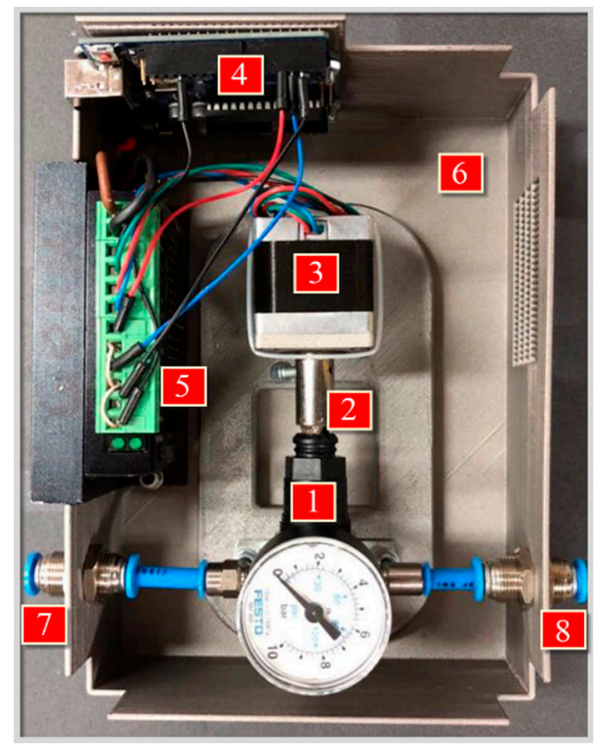

(a)

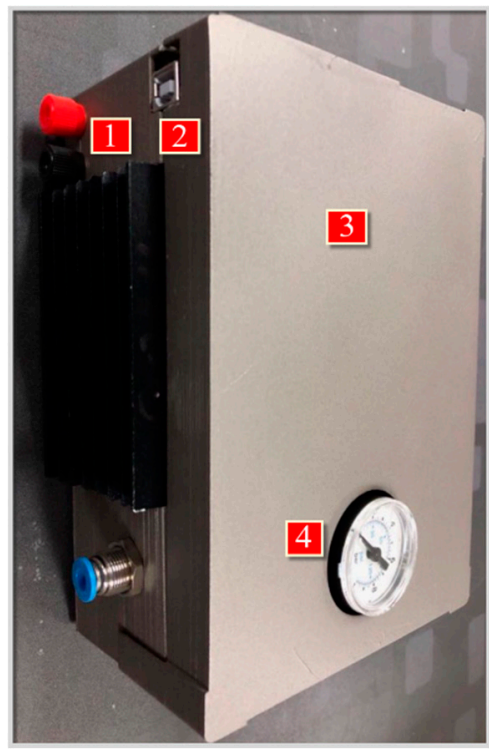

(b)

Figure 4. Automatically controlled pressure regulator (a) without the cover: (1) Pressure regulator, (2) Coupling, (3) Stepper motor, (4) Microcontroller, (5) Motor driver, (6) Plastic housing, (7) Compressed air inlet, and (8) Outlet connector (b) with the cover: (1) Power supply connector, (2) Microcontroller port, (3) Plastic cover, and (4) Hole for the pressure regulator. Reproduced from [4], Springer: in press.
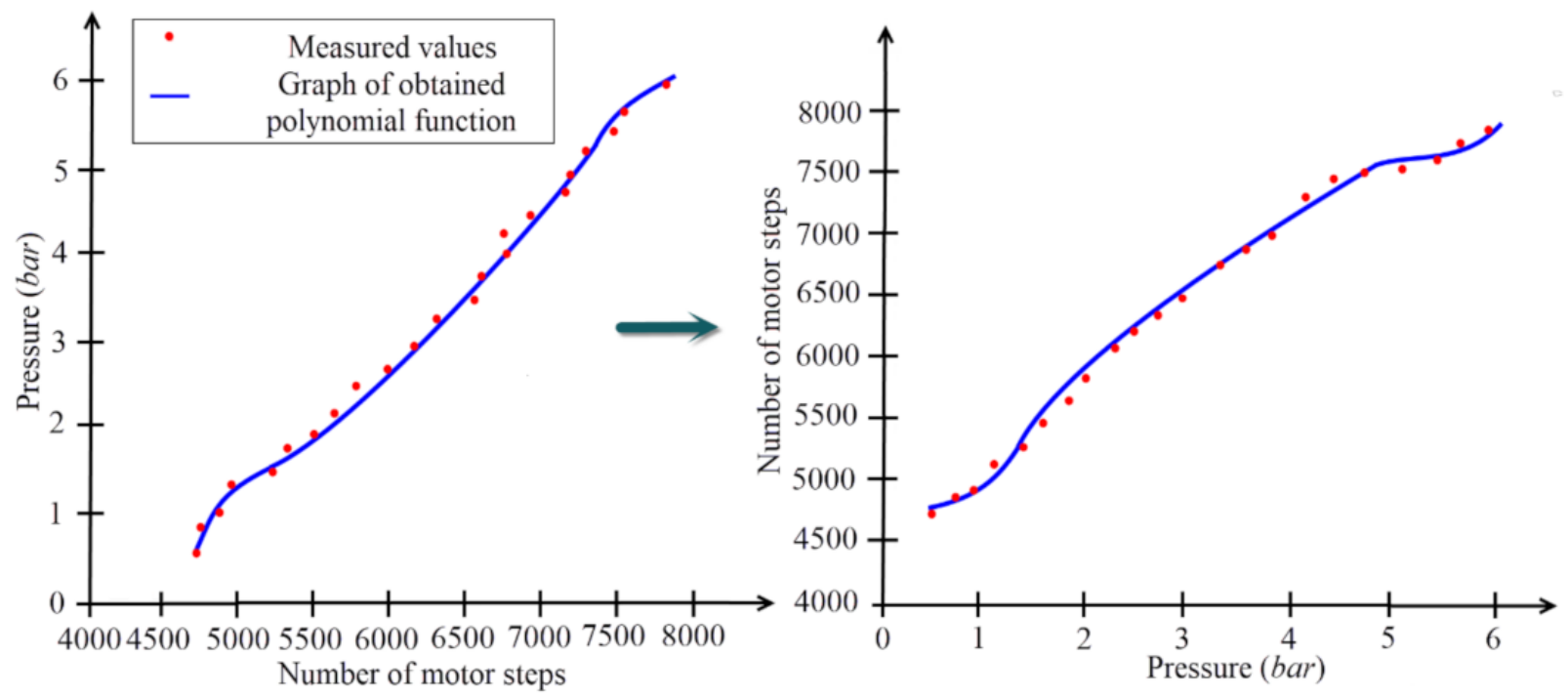

Figure 5. Transformation of polynomial function presenting the dependence of outlet pressure from number of steps of the stepper motor to the inverse polynomial function. Reproduced from [4], Springer: in press.

\subsection{RFID Sensor Assembly}

For identifying the current workpiece in the storage (the workpiece that will be handled by the manipulator), different technologies can be used, such as machine vision, digital checkweigher, barcode and QR code scanners, RFID technology, different types of sensors, etc. Since the weights of the workpieces are known (from the technical specification), in this case, RFID technology is used and a new device, RFID sensor assembly was developed (Figure 6). This way, reading the information about the weight of the workpieces from the 
RFID tags that were attached to them is intended for implementation in pneumatic circular manipulator. It is important to mention that the appropriate information was previously written on the tags, which are in the form of stickers.

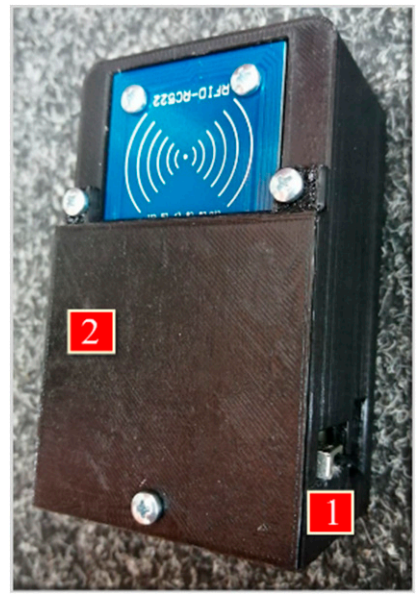

(a)

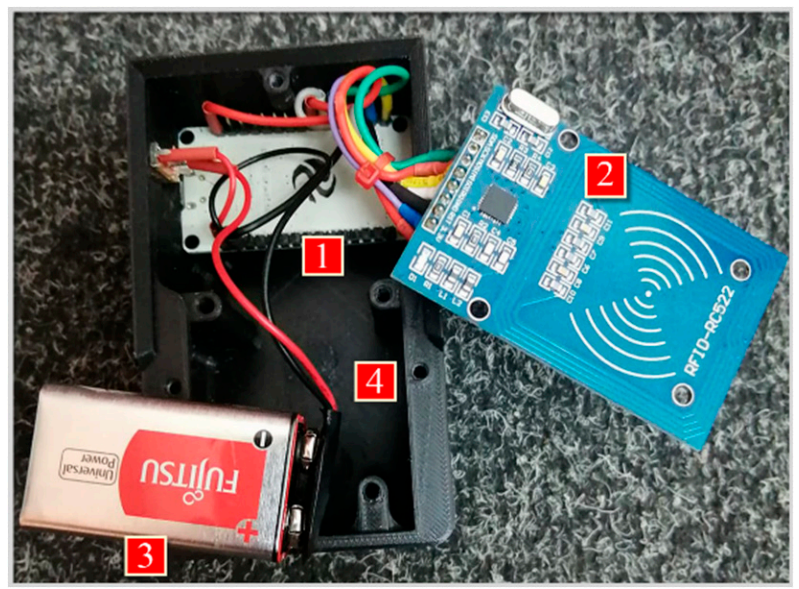

(b)

Figure 6. RFID sensor assembly (a) with the cover: (1) On/off switch and (2) Plastic cover (b) without the cover: (1) Microcontroller, (2) RFID module, (3) Power source, and (4) Plastic housing.

Based on the information read from the tag that shows which of the three types of workpieces is in the storage, the system can change the air pressure level accordingly, so that the workpiece can be handled with necessary pressure.

The reader collects data from the RFID tags with the frequency of $13.56 \mathrm{MHz}$. It can be connected to a computer in one of the two ways:

- UART/USB protocol and

- Bluetooth protocol.

\subsection{Software and the Developed Application \\ 2.4.1. User Application}

To be able to extract and use the information from the RFID tags, a Java application was developed (Figure 7). Information about the application, such as the list of commands or a user manual, are found in the "INFO" option list (Figure 7, position 2). The application user interface offers a choice of the type of communication, UART/USB or Bluetooth (Figure 7, position 1), after which it notifies the user whether the connection was successful or not. For establishing or ending connection between the RFID system and the computer, "Connect" (Figure 7, position 3) or "Disconnect" (Figure 7, position 4) buttons are used. The user also needs to choose the type of command (Figure 7, position 8) that will be sent (Figure 7, position 7) to the reader by entering one of the four possible commands in the textbox:

- Idle (sets the reader to inactive state),

- Run (sets the reader to active state),

- Prog (sets the reader to the mode of downloading program to the memory card), and

- Write (sets the reader in the mode of writing information into the tag).

In the main panel of the application, there is a list of commands sent (Figure 7, position 6) to the reader and a list of system responses: "OK" or "FAILED" (Figure 7, position 5).

Once the reader is successfully connected to a computer and set to run mode (active state), it will detect the RFID tag attached to the workpiece once the tag is positioned within $15 \mathrm{~mm}$ distance from the reader and the application interface will write out the type of the detected workpiece in the list of commands. 


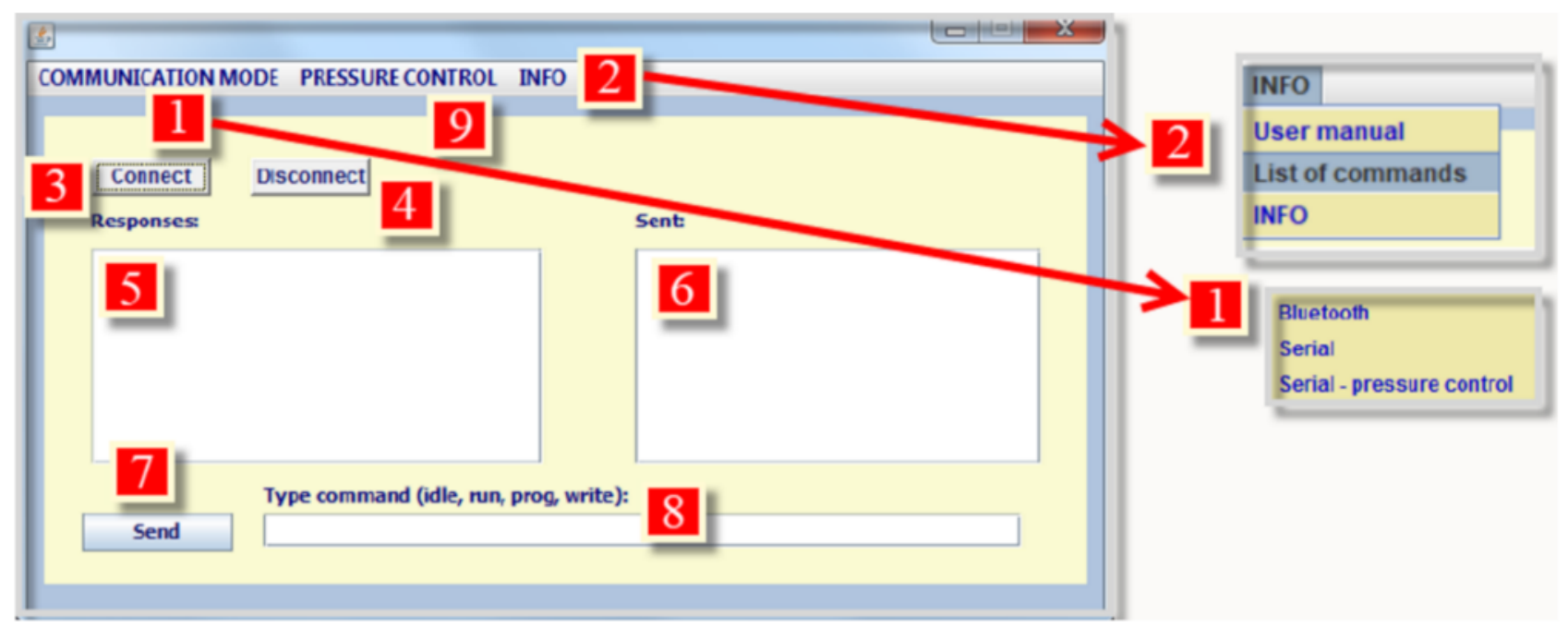

Figure 7. User application.

In order to adjust the compressed air pressure based on the type of the detected workpiece, the automatically controlled pressure regulator also needs to be connected to the computer, and the appropriate port has to be chosen from the port list after clicking on the "PRESSURE CONTROL" option (Figure 7, position 9). The appearance of the new window is shown in Figure 8.

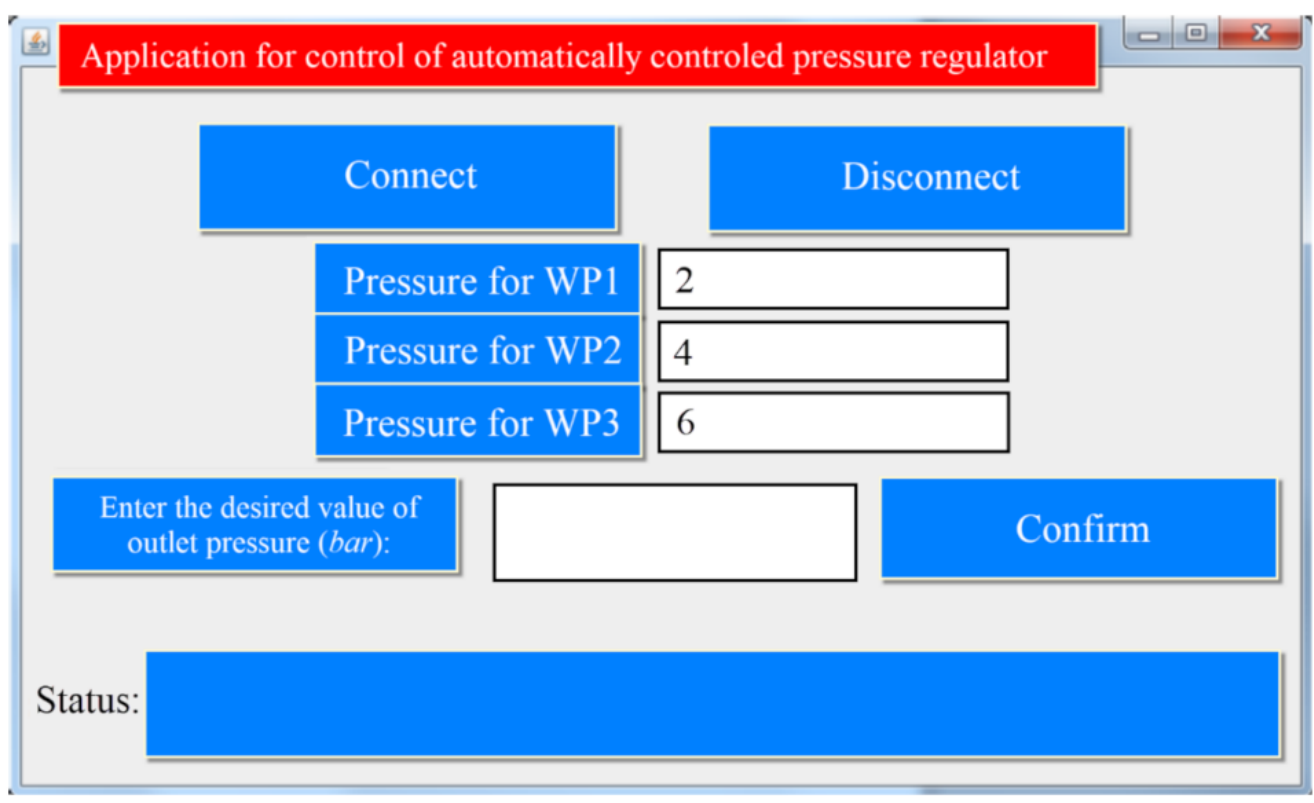

Figure 8. Pressure control panel.

As can be seen from Figure 8, the application offers two operating modes: automatic and manual. Automatic mode sends the required pressure value (shown in the labels) to the computer automatically once the workpiece is detected, i.e., the information about the type of the workpiece has been read from the tag. In the cases when it is not possible to read information from the tag in the defined time interval, the pressure value is automatically set to 6 bar. On the other hand, manual mode serves as a backup option for pressure regulation. This option requires the user to enter the pressure value into the textbox, and if the entered value is within the range 0-6 bar, the command is sent to the automatically controlled pressure regulator. Otherwise, the application will notify the user about the incorrect input. 


\subsubsection{Program for PLC}

The program code for the PLC in control of the manipulator was written using Festo FST version 4.21 in a form of a statement list, according to the travel-step diagram (Figure 1b).

\subsection{The Ways of Communication}

The ways of communication in the system are shown in Figure 9. After the detection of the workpiece by the RFID sensor assembly, the obtained information is transferred to the PC on which the user application is installed, using RS232 or Bluetooth. The information about the required pressure level, which depends on the detected workpiece, is forwarded to the automatically controlled pressure regulator that adjusts the outlet pressure level accordingly, also using RS232. Adjusting the required pressure level on the pressure regulator is in accordance with the control cycle of the circular manipulator, which is controlled by PLC. Namely, adjusting pressure level for cylinder C extracting is done when cylinder $\mathrm{C}$ is retracted, while other cylinders are executing the appropriate operations in accordance with the travel-step diagram (Figure 1b).

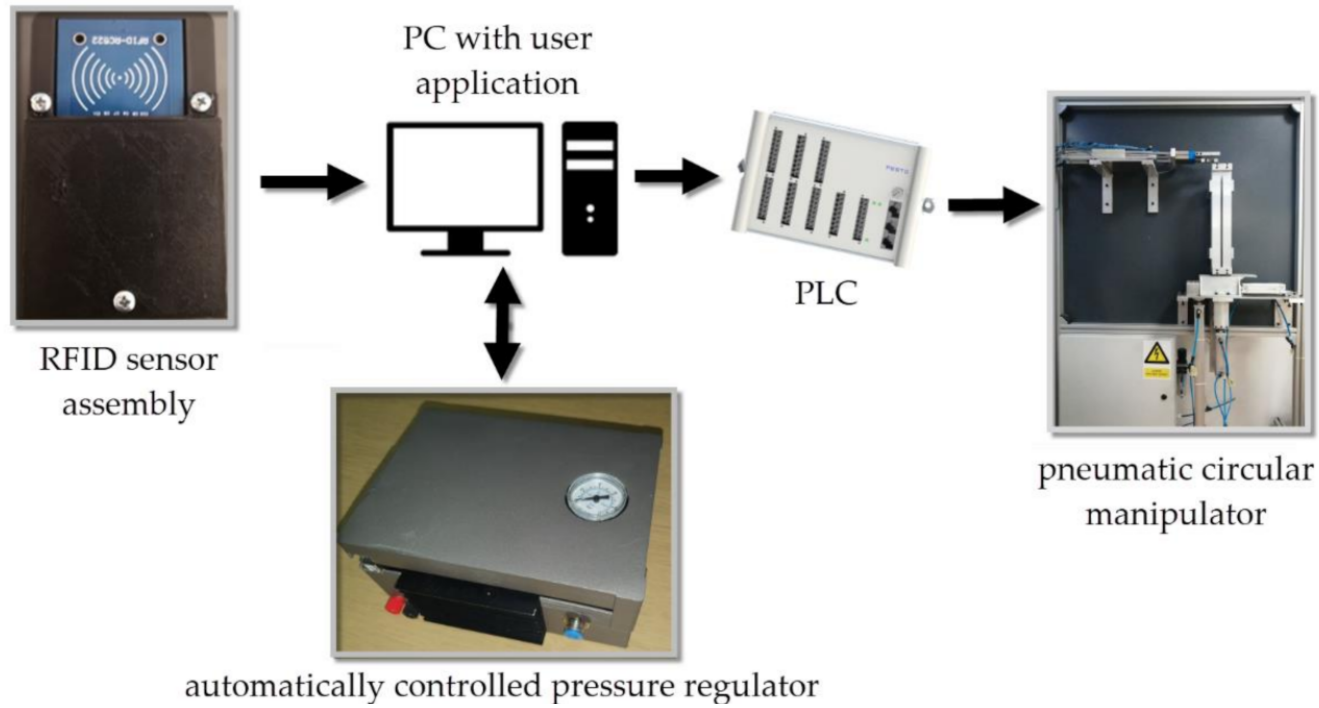

Figure 9. Ways of communication.

\section{Analysis of the Obtained Results and Discussion}

The aim of the performed experiments was to determine the reduction of compressed air consumption achieved by using the automatically controlled pressure regulator, and also to determine whether the implementation of this device has an effect on the operating time of the manipulator, i.e., whether it will cause a delay in cycle performing and decrease its productivity. All research was done using the previously described control system and devices, connected into one integrated system (Figure 10), in order to simulate a smart automatic production process.

The pneumatic control scheme of this experimental setup is shown in Figure 11. The automatically controlled pressure regulator and quick exhaust valve are marked as 3V3 and 3V2 and circled with red lines, respectively. The position of the AirBox device is also presented in this scheme, circled with a red line.

As in the Industry 4.0 concept, the workpieces may appear in any order and the size of the production series can be arbitrarily small. In an extreme case, it can be one, the parameters (i.e., the operating pressure), which need to be adjusted in a period of time shorter than the time of performing one manipulator cycle. In this case, the adjustment of the operating pressure is performed when cylinder $C$ is retracted, as was previously mentioned. Expectedly, the time required for adjusting air pressure level depends on the difference between current and required pressure level for two sequential workpieces. 


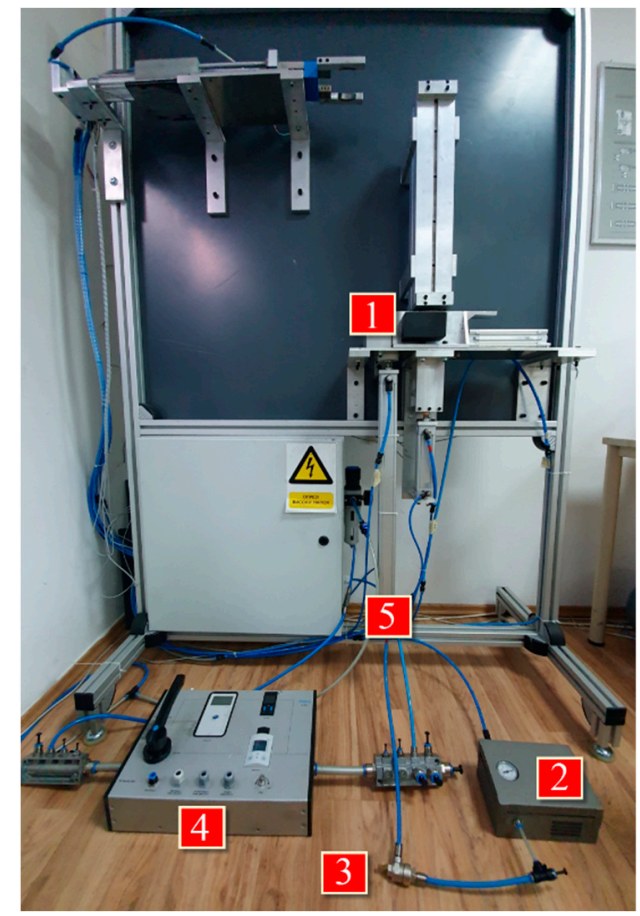

Figure 10. Integrated experimental setup: (1) RFID sensor assembly, (2) Developed pressure regulator, (3) A quick exhaust valve, (4) Festo AirBox, and (5) Cylinder C.

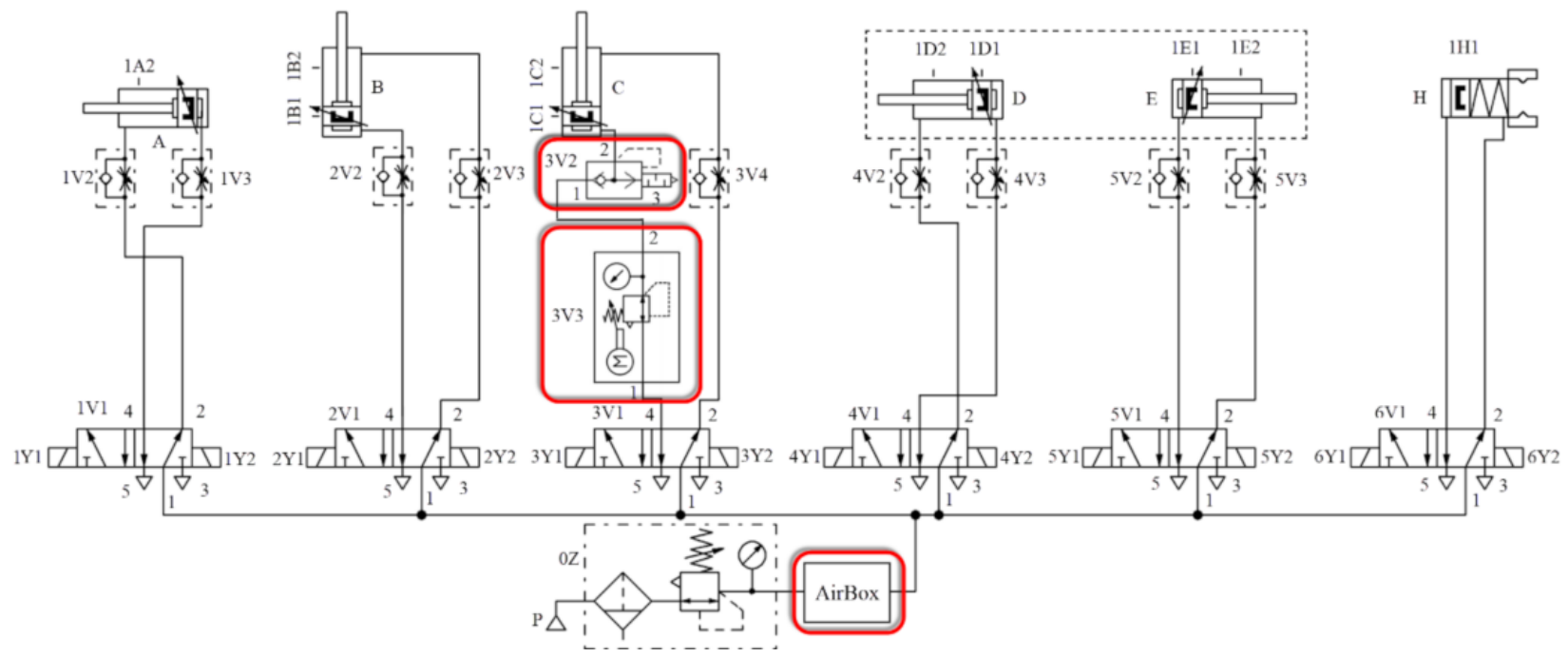

Figure 11. Pneumatic scheme of the experimental setup.

Due to these reasons, the first step of this research was determining the time needed for adjusting the air pressure level on the regulator. As this research was focused on actuator operating at three different pressure levels ( 2 bar, 4 bar, and 6 bar), Table 2 shows the periods of time required for pressure regulation depending on the current and required pressure levels.

Based on the results shown in Table 2, the longest period of time $(2.3 \mathrm{~s})$ required for making a change of 4 bar can be seen, i.e., adjusting the pressure level from 2 bar to 6 bar and vice versa. As the time period between detecting the new workpiece positioned in station for the beginning of a new cycle and cylinder $C$ extracting is $3.2 \mathrm{~s}$, the general conclusion is that the use of the newly developed automatically controlled pressure regulator does not affect the operating speed of the given system, i.e., it does not slow down the system. 
Table 2. Time required for compressed air pressure regulation depending on the operating pressure value.

Range of Pressure Alteration (bar)

Time Required for Changing the Outlet Pressure Level (s)

2 (implies pressure change between 2 bar and 4 bar, also between 4 bar and 6 bar)

4 (implies pressure change between 2 bar and 6 bar)

In order to determine the energy efficiency and productivity of the circular manipulator, a series of tests were done, measuring the compressed air consumption and cycle time. Compressed air flow was determined using the Festo AirBox device, which defines the sample time period and provides results (time, air flow) in .csv and .jpg format (Figure 12).

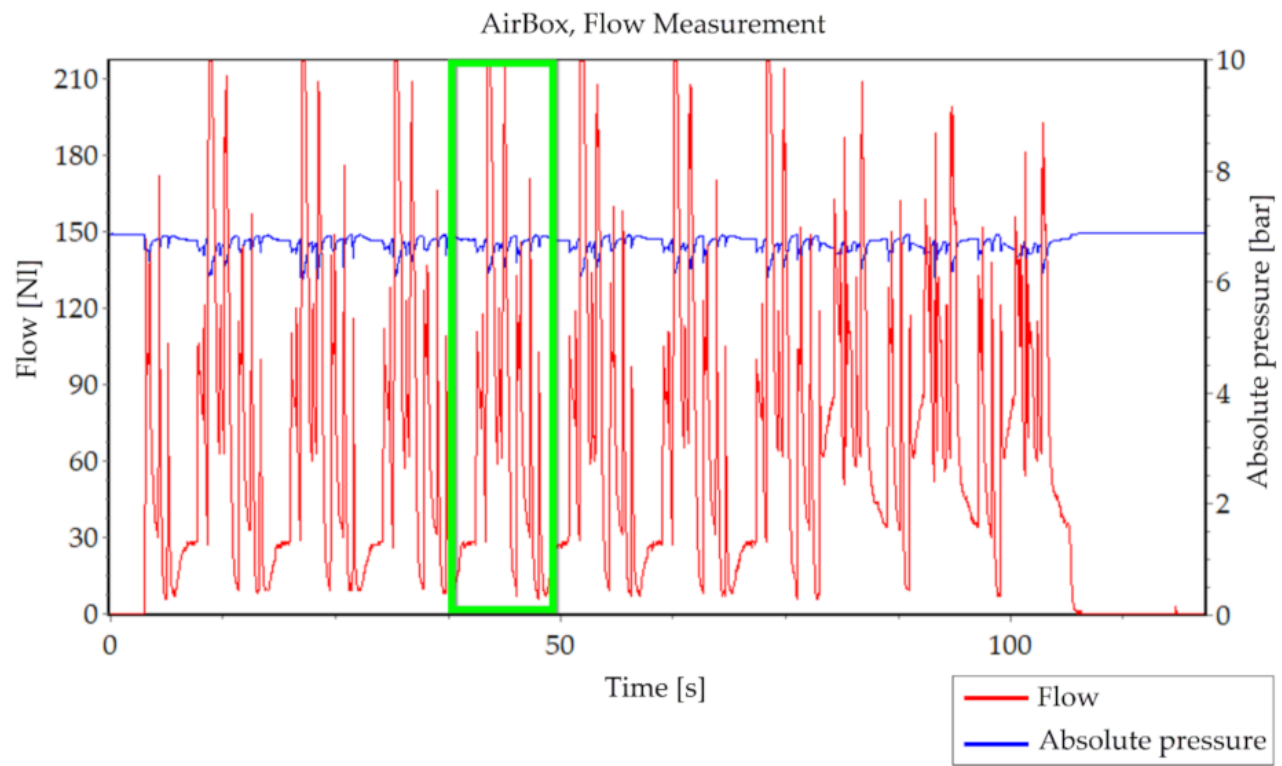

Figure 12. AirBox graph display of compressed air flow measured (red line) and absolute operating pressure (blue line) during one of the tests.

The manipulator executed ten cycles in which these values were measured. For easier understanding, in Figure 12, one of the cycles was marked with a green rectangle. In order to determine total compressed air consumption, the values shown in the graph need to be integrated to determine the surface below the curve (using the definite integral). Consequently, total compressed air consumption was calculated using the following equation:

$$
Q=\frac{1}{2} \sum_{i=1}^{n}\left(t_{i}-t_{i-1}\right)\left(q_{i}+q_{i-1}\right)
$$

where $Q$ is the compressed air consumption (l), $t_{i}$ and $t_{i-1}$ are sequential sampling times (s), and $q_{i}$ and $q_{i-1}$ are the values of compressed air flow sampled at $t_{i}$ and $t_{i-1}(1 / \mathrm{min})$. Based on these results, average compressed air consumption per cycle (10th part of total consumption) as well as average cycle duration time were determined for all tests. Each test was repeated five times in order to get reliable results.

In the experiment, the workpieces were set to appear in different order each time so that an arbitrary combination of workpieces could be simulated. The tests were done with 10 different combinations of workpiece appearance, shown in Table 3. 
Table 3. Combinations of workpiece appearance.

\begin{tabular}{ccc}
\hline No. of Combination & Combination of WP & Operating Pressure (bar) \\
\hline I & $3-3-3-3-3-3-3-3-3-3$ & 6 \\
II & $2-2-2-2-2-2-2-2-2-2$ & 4 \\
III & $1-1-1-1-1-1-1-1-1-1$ & 2 \\
IV & $1-1-1-3-1-1-1-1-3-1$ & $2-6-2-6-2$ \\
V & $1-2-1-2-1-3-1-2-3-2$ & $2-4-2-4-2-6-2-4-6-4$ \\
VI & $2-2-3-1-2-2-1-3-1-2$ & $4-6-2-4-2-6-2-4$ \\
VII & $3-3-3-1-3-3-2-3-3-3$ & $6-2-6-4-6$ \\
VIII & $1-3-3-3-3-3-3-1-3-3$ & $2-6-2-6$ \\
IX & $3-3-3-3-2-3-2-3-3-3$ & $6-4-6-4-6$ \\
X & $1-2-3-2-1-3-1-3-2-1$ & $2-4-6-4-2-6-2-6-4-2$ \\
\hline
\end{tabular}

The average compressed air consumption per cycle values are listed in Figure 13.

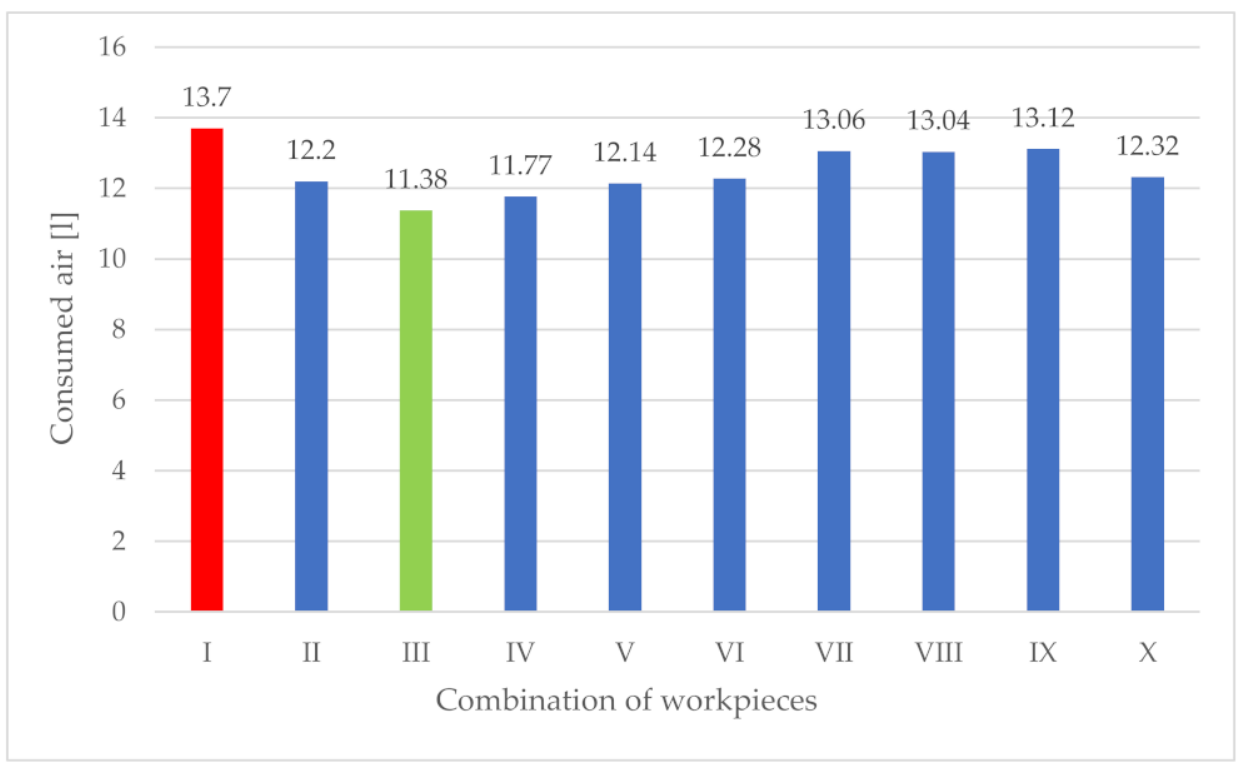

Figure 13. Average compressed air consumption of the system per cycle.

As it is displayed in Figure 13, the highest compressed air consumption is measured when the automatically controlled pressure regulator is set to pressure level of 6 bar, i.e., when the manipulator is handling the heaviest workpieces (combination I, red color) and equals $Q_{I}=13.71$. The lowest consumption value was achieved when handling the lightest workpieces at 2 bar (combination III, green color) and equals $Q_{I I I}=11.381$. In comparison to the theoretical compressed air consumption (Table 1), the real consumption in these cases is higher $\left(Q_{I}=13.71>Q_{t I}=10.536 \mathrm{l} ; Q_{I I I}=11.381>Q_{t I I I}=8.631 \mathrm{l}\right)$, which is in accordance with the expectations, since only the volume of the actuators is considered during calculations of the theoretical consumption. Under real conditions, there are pressure decrease, "dead volume" (the remaining volume when the piston reaches the end of its stroke), potential air leakage, etc., so the real consumption is higher. Additionally, these two combinations (combinations I and III) present extreme cases of compressed air consumption (minimum and maximum values) for the given system, and their difference presents the highest possible consumption savings:

$$
\Delta Q=Q_{I}-Q_{I I I}=13.71-11.381=2.321
$$

Percentual savings value is then calculated as:

$$
Q_{s}[\%]=\frac{\Delta Q}{Q_{I}} \times 100 \%=\frac{2.321}{13.71} \times 100 \%=16.9 \%
$$


Otherwise, the measured compressed air consumption values (combinations II and from IV to X) were lower than the maximum, which shows that even in these cases, there are energy savings. The percentage of those savings depends on the product mix, and its value can be up to $16.9 \%$. Consequently, larger participation of the lightest products in the product mix causes reduced compressed air consumption, as well as increased energy efficiency of the system, and vice versa.

The $16.9 \%$ reduction of total compressed air consumption presents significant savings and is achieved by lowering the operating pressure in only one cylinder (cylinder C). If the operating pressure in other cylinders were lowered, as well, the energy savings would be even higher.

Since operating pressure reduction causes the decrease of operating speed of pneumatic actuators, cycle times at different operating conditions were measured. The average cycle times of the manipulator for the given combinations of workpieces are given in Figure 14.

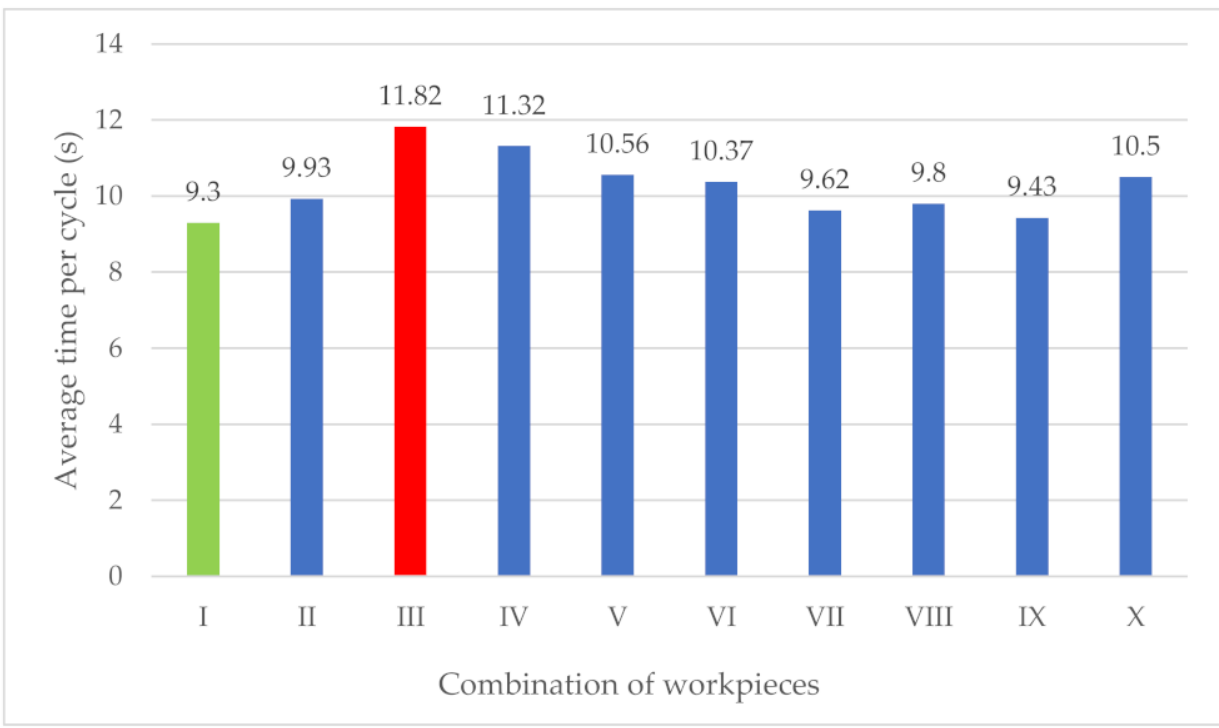

Figure 14. Average cycle time of the manipulator.

It can be noticed that the cycle duration is the shortest in the case when cylinder $\mathrm{C}$ operating pressure is set to 6 bar (combination I, green color) and equals $t_{I}=9.3 \mathrm{~s}$. This is in accordance with the expectations, as higher-pressure levels condition higher speed [1]. At the pressure level of 2 bar, the cycle time is the longest (combination III, red color) and equals $t_{I I I}=11.82 \mathrm{~s}$. These two combinations present extreme cases of cycle times (minimum and maximum values) for the given system and their difference presents the highest possible time delay:

$$
\Delta t=t_{I I I}-t_{I}=11.82 \mathrm{~s}-9.3 \mathrm{~s}=2.52 \mathrm{~s}
$$

Percentual time delay $\left(t_{d}\right)$ is then calculated as:

$$
t_{d}[\%]=\frac{\Delta t}{t_{I I I}} \times 100 \%=\frac{2.52 \mathrm{~s}}{11.82 \mathrm{~s}} \times 100 \%=21.31 \%
$$

These values show that the longest time delay per cycle equals $\Delta t=2.52 \mathrm{~s}$. Otherwise (combinations II and from IV to X), there are also time delays, but their values are shorter. Consequently, larger participation of the heaviest products in the product mix causes shorter cycle times and vice versa. 


\section{Conclusions}

Constant alterations of quantity, shape, dimension, and weight of workpieces, characteristic of working in conditions of flexible pneumatic systems, cause the need for different operating pressure levels in the system. Compressed air pressure reduction has a great impact on increasing energy efficiency of the entire system. If operating pressure is regulated in real time, the use of the automatically controlled pressure regulator in compressed air systems can provide significant savings in terms of compressed air consumption.

As can be seen from the obtained results, reduction of operating pressure in only one cylinder (cylinder C) to the optimal value required for lifting the workpieces of lower mass than those on the basis of which the system was dimensioned can attribute to reduction of total compressed air consumption up to $16.9 \%$. The reduction of compressed air consumption varies from case to case and largely depends on the product mix.

On the other hand, operating pressure reduction in the system, expectedly, leads to the increase of the cycle duration period. Cycle duration time depends on the task and the specifics of the process conditions in which the system takes place. In this particular case, the cycle duration period increased up to $2.52 \mathrm{~s}$, but this value can be significantly reduced if the movements of the cylinders in the system are overlapped, which requires careful planning.

Cost-effectiveness analysis of the suggested system was not in focus of this paper. However, considering the relatively small investments regarding the required equipment and the high costs of compressed air use, it is easy to conclude that the ROI period for the given investment would be relatively small, as well.

$\mathrm{ROI}$ is shortened in the following cases:

- When cylinders with large piston diameters are used,

- When weight differences of the workpieces in use are significant,

- When the participation of heavy workpieces in the product mix is small,

- When the number of work cycles is high.

Considering that the research results show that compressed air pressure reduction in accordance with variable requirements conditions, causes a significant reduction of compressed air consumption, making the system more energy efficient, while in some cases there are cycle time delays, the users are given the option of implementing this approach in accordance with their system characteristics.

Author Contributions: S.D. and V.R. conceived and designed the experiments; N.D. and V.R. performed experiments; D.Š. and V.B. analyzed the data; N.D., S.D. and D.Šs. wrote the paper; V.R. and V.B. modified the manuscript. All authors have read and agreed to the published version of the manuscript.

Funding: This research received no external funding.

Institutional Review Board Statement: Not applicable.

Informed Consent Statement: Not applicable.

Data Availability Statement: Not applicable.

Conflicts of Interest: The authors declare no conflict of interest.

\section{References}

1. Ebel, F.; Idler, S.; Prede, G.; Scholz, D. Pneumatik Elektropneumatik-Grundlagen. In Bildungsverlag EINS, Festo, 3rd ed.; Bildungsverlag EINS GmbH: Troisdorf, Germany, 2017.

2. Saidur, R.; Rahim, N.A.; Hasanuzzaman, M. A review on compressed-air energy use and energy savings. Renew. Sustain. Energy Rev. 2010, 14, 1135-1153. [CrossRef]

3. Radgen, P.; Blaustein, E. Compressed Air Systems in the European Union, Energy, Emissions, Savings Potential and Policy Actions; Fraunhofer Institute for Systems Technology and Innovation, LOGUL X Verlag GmbH: Stutgart, Germany, 2001.

4. Reljić, V.; Knežević, P.; Šešlija, D.; Dudić, S. Improving the Energy Efficiency of Pneumatic Control Systems by Using Remotelycontrolled Pressure Regulator. In Proceedings of the 18th International Scientific Conference on Industrial Systems-Industrial Innovation in Digital Age, Novi Sad, Serbia, 7-9 October 2020; Faculty of Technical Sciences: Novi Sad, Serbia, 2020. in press. 
5. Reljić, V.; Bajči, B.; Milenković, I.; Šulc, J.; Šešlija, D.; Dudić, S. Development of an Experimental Setup for Remote Testing Pneumatic Control. Int. J. Online Eng. 2018, 14, 195-202. Available online: https://online-journals.org/index.php/i-joe/article/ view/7784 (accessed on 20 January 2021). [CrossRef]

6. Kagermann, H.; Lukas, W.D.; Wahlster, W. Industrie 4.0: Mit dem Internet der Dinge auf dem Weg zur 4. Industriellen Revolution. Available online: https:/ / www.vdi-nachrichten.com/Technik-Gesellschaft/Industrie-40-Mit-Internet-Dinge-Weg-4industriellen-Revolution (accessed on 12 November 2020).

7. Industrie 4.0 Working Group. Recommendations for Implementing the Strategic Initiative INDUSTRIE 4.0-Final Report of the Industrie 4.0 Working Group. Forschungsunion \& Acatech. 2013. Available online: https:/ /www.din.de/blob/76902/e8cac883f4 2bf28536e7e8165993f1fd/recommendations-for-implementing-industry-4-0-data.pdf (accessed on 3 February 2021).

8. Rojko, A. Industry 4.0 Concept: Background and Overview. Int. J. Interact. Mob. Technol. 2017, 11, 77-90. Available online: https:/ / online-journals.org/index.php/i-jim/article/view/7072 (accessed on 20 January 2021). [CrossRef]

9. Liao, Y.; Deschamps, F.; de Loures, E.F.R.; Ramos, L.F.P. Past, present and future of Industry 4.0-a systematic literature review and research agenda proposal. Int. J. Prod. Res. 2017, 55, 3609-3629. [CrossRef]

10. Zhong, R.Y.; Xu, X.; Klotz, E.; Newman, S.T. Intelligent Manufacturing in the Context of Industry 4.0: A Review. Engineering 2017, 3, 616-630. [CrossRef]

11. Zelenović, D. Flexibility-A condition for effective production systems. Int. J. Prod. Res. 1982, 20, 319-337. [CrossRef]

12. Groover, M. Automation, Production Systems and Computer Integrated Manufacturing, 2nd ed.; Prentice Hall: Bergen County, NJ, USA, 2001.

13. De Toni, A.; Tonchia, S. Manufacturing flexibility: A literature review. Int. J. Prod. Res. 1998, 36, 1587-1617. [CrossRef]

14. Brill, P.H.; Mandelbaum, M. On measures of flexibility in manufacturing systems. Int. J. Prod. Res. 1989, 27, 747-756. [CrossRef]

15. El Maraghy, H.A. Flexible and reconfigurable manufacturing systems paradigms. Int. J. Flex. Manuf. Syst. 2006, 17, 261-276. [CrossRef]

16. Fernandes, R.; Gouveia, J.B.; Pinho, C. Product mix strategy and manufacturing flexibility. J. Manuf. Syst. 2012, 31, 301-311. [CrossRef]

17. Yang, F.; Tadano, K.; Li, G.; Kagawa, T.; Peng, J. Simulation on the Characteristics of Pneumatic Booster Valve with Energy Recovery. In Proceedings of the 16th Asia Simulation Conference and SCS Autumn Simulation Multi-Conference, Beijing, China, 8-11 October 2016; pp. 143-153.

18. Yang, F.; Tadano, K.; Li, G.; Kagawa, T. Analysis of the Energy Efficiency of a Pneumatic Booster Regulator with Energy Recovery. Appl. Sci. 2017, 7, 816. [CrossRef]

19. Luciano, E.; Victor, J.; De, N.; Eugênio, B.C. Compressed air saving in symmetrical and asymmetrical pneumatic positioning systems. Proc. Inst. Mech. Eng. Part I 2015, 229, 957-969. [CrossRef]

20. Wang, Z.; Xiong, W.; Wang, H. Exergy analysis of the pneumatic line throwing system. Int. J. Exergy 2017, 19, 364-379. [CrossRef]

21. Shen, X.; Goldfarb, M. Energy Saving in Pneumatic Servo Control Utilizing Interchamber Cross-Flow. J. Dyn. Syst. Meas. Control 2007, 129, 303-310. [CrossRef]

22. Yang, A.; Pu, J.; Wong, C.B.; Moore, P. By-pass valve control to improve energy efficiency of pneumatic drive system. Control Eng. Pract. 2009, 17, 623-628. [CrossRef]

23. Šešlija, D.; Čajetinac, S.; Blagojević, V.; Šulc, J. Application of pulse width modulation and by-pass valve control for increasing energy efficiency of pneumatic actuator system. Proc. Inst. Mech. Eng. Part I 2018, 232, 1314-1324. [CrossRef]

24. Kanno, T.; Hasegawa, T.; Miyazaki, T.; Yamamoto, N.; Haraguchi, D.; Kawashima, K. Development of a Poppet-Type Pneumatic Servo Valve. Appl. Sci. 2018, 8, 2094. [CrossRef]

25. Dudić, S.; Ignjatović, I.; Šešlija, D.; Blagojević, V.; Stojiljković, M. Leakage Quantification of Compressed Air Using Ultrasound and Infrared Thermography. Measurement 2012, 45, 1689-1694. [CrossRef]

26. Blagojevic, V.; Seslija, D.; Dudic, S.; Randjelovic, S. Energy Efficiency of Pneumatic Cylinder Control with Different Levels of Compressed Air Pressure and Clamping Cartridge. Energies 2020, 13, 3711. [CrossRef]

27. Harris, P.; Nolan, S.; O’Donnell, G.E. Energy optimization of pneumatic actuator systems in manufacturing. J. Clean. Prod. 2014, 72, 35-45. [CrossRef]

28. Dvorák, L.; Fojtášek, K. Pressure Regulators as Valves for Saving Compressed Air and their Influence on System Dynamics. EPJ Web Conf. 2015, 92, 02015. [CrossRef] 